\title{
The basic principles of construction and the structure of the system for remote monitoring of the state of soils of grape agrocenoses
}

\author{
Igor Grishin ${ }^{1, *}$ and Rena Timirgaleeva ${ }^{1}$ \\ ${ }^{1}$ Lomonosov Moscow State University, GSP-1, Leninskie Gory, 119991 Moscow, Russia
}

\begin{abstract}
The article solves the urgent problem of developing a system for remote monitoring of the soil conditions of grape agrocenoses in the southern regions of Russia. It is shown that such monitoring is required to be carried out constantly because of the high anthropogenic load and critical decrease in soil fertility. Experimental studies showing the possibility of satellite remote monitoring of the soil conditions have been carried out, while the accuracy of determining the humus content in the soil when shooting with a camera in a laboratory and using satellite images obtained with multispectral equipment is no worse than 10-20 percent compared to chemical laboratory methods. For the experiment, 22 experimental plots, the condition of the soil on which was determined in the laboratory according to Tyurin and by shooting and processing images of a high-resolution digital camera, were laid. Synchronous data from the Russian satellite Kanopus-V were studied for the same areas. Analytical dependences of the humus content in the soil on the brightness level of the red spectral channel were obtained. The structure of the information system for remote satellite monitoring of the soil conditions in the region is proposed.
\end{abstract}

\section{Introduction}

Throughout the history of land use on our planet, one can see a pattern associated with changes in land use technologies, climate change, which ultimately leads to a constant loss of soil organic matter [1], the main representative of which is humus (85-90\% of the total). Moreover, it is the content of organic matter in the soil that is an integral indicator of its fertility [2].

To determine the content of organic carbon in the soil of the monitored areas, direct methods, including the collection of soil samples in the field, and their subsequent laboratory analysis, are usually used. Humus has been identified as the most important component for viticulture by numerous soil fertility researchers. High levels of organic carbon (humus, as the principal representative) in the soil determine the high yield of both agricultural production in general and viticulture.

This is determined by the following factors: increasing the soil's ability to retain moisture; increasing the level and availability of nutrients used by plants; improving the physical

\footnotetext{
* Corresponding author: igugri@gmail.com
} 
properties of the soil with an increase in the humus content in it. All this determines the health of the soil cover of the grape agrocenosis [2].

At the same time, the applied agricultural production systems, traditional vineyard soil cultivation systems, and irrational fertilization very often have a negative effect on the level of humus in the soil, on the level of organic carbon in it, which leads to a significant deterioration in the physical and chemical properties of the soil.

Intensive land use often leads to the development of unfavorable processes (water and wind erosion, secondary salinization and water logging, soil pollution with industrial emissions and pesticides), which significantly worsens the properties of the soil cover. In this regard, it becomes necessary to monitor the indicators of soil condition in order to assess it, predict and map it, and to justify measures to improve soil fertility. Monitoring of soil cover includes systematic observations of the level of soil pollution, migration processes of chemicals, dynamics of soil fertility indicators in space and time. However, it cannot be limited only to the analysis of soil samples, since the study of soils is inseparable from the study of other components of the landscape, all the ways of accumulation of pollutants in both natural and anthropogenic complexes.

A significant number of works of domestic and foreign scientists and researchers are devoted to the issues of preserving and restoring the fertility of agrocenoses. There are works devoted to remote assessment of the soil conditions, several researchers have applied the results of remote sensing of the Earth from space to monitor soil fertility, soil mapping, and the state of vineyards.

A study by Australian researchers [3] indicates that monitoring and mapping soil organic carbon is important because land management and fluctuations in precipitation can significantly alter soil organic carbon (SOC) levels. Their research aims to monitor ten-year SOC changes in the semi-arid irrigated cotton region of Australia under a variety of land uses. A multivariate linear mixed model was used to model SOC content with four response variables. The ability of this model to show the relationship between different soil properties, soil depth and time points makes them promising for spatio-temporal soil monitoring.

It is noted in works $[4,5]$ that satellite remote sensing is a useful tool for determining the spatio-temporal distribution of soil quality parameters in large agricultural areas. This study showed that the combined use of Landsat- 8 and Sentinel-2 satellites makes it possible to use them effectively to monitor SOC and the dynamics of changes in soil quality in extensive areas.

The issues of determining the loss of soil and soil organic carbon as a result of wind erosion, as well as the need for monitoring organic carbon in the soil, are considered in [6, 7]. SOC loss is noted as a serious problem in monoculture growing areas in northern Germany. The results of monitoring and modeling are in good agreement. It is noted that the growing human demand for soil ecosystem services requires reliable data on global soil resources for sustainable development. SOC stock is a key indicator of soil quality as it affects important biological, chemical and physical functions of the soil.

The authors [8] argue that SOC dynamics affect soil quality, agricultural productivity and $\mathrm{CO}_{2}$ concentration in the atmosphere. Despite the need for spatial estimates of SOC content over time, reliable estimates using traditional field research methods are limited by data availability because measurements are often made at discrete points, large sample spacing, or confined spaces. Remote sensing (RS) is well positioned to provide spatially distributed, repeatable, scaled and resource efficient measurements of SOC content and fluxes at field, landscape and regional scales. This article aims to provide transparent assessment and practical guidance on RS methods and products with the aim of further advancing and better incorporating RS methods into soil science. 
A number of works by authors from various countries [9-13] are devoted to individual, sometimes rather narrow, aspects of using the results of remote sensing from satellite to monitor some indicators characterizing the quality of soils.

At the same time, it should be noted that complex works where the problem of monitoring the soil conditions of grape agrocenoses in the southern regions of Russia would be considered at the level of creating a monitoring system that includes hardware and corresponding specialized software are currently not presented in international scientific information databases and citation systems.

\section{Materials and Methods}

In this work, an attempt to develop the foundations of a methodology for assessing the humus content of grape agrocenoses in the southern regions of Russia is made. At the same time, the assessment of humus content was carried out both in laboratory conditions and based on a space spectrozonal survey.

The objects of research at the first stage were the soils of grape agrocenoses in the southern regions of Russia. In total, 22 experimental plots were set up in the region where soil samples were taken for laboratory research. At the moment, processing of information related to 4 experimental sites has been carried out. The characteristics of the soils and geographic data of the considered experimental plots are shown in Table 1.

In each case, samples were taken from the upper layer from a depth of 5-15 centimeters. The humus content was determined according to Tyurin in accordance with Russian Standard 26213-91. Soils. Methods for the Determination of Organic Matter.

The spectral characteristics of the studied soils were determined on the basis of the MSS multispectral imaging equipment (spectral range is $460-860 \mathrm{~nm}$ ) of the Kanopus-V satellite (the survey time was synchronized with the time of soil sampling, archived data were used), and in laboratory conditions using a digital camera Canon DS126181. The focal length of the camera lens was $55 \mathrm{~mm}$, the resolution was $4272 \times 2848$ pixels, and the spectral range of the matrix was $400-780 \mathrm{~nm}$.

Table 1. Characteristics of plots and soils.

\begin{tabular}{|c|c|c|c|}
\hline \begin{tabular}{|l|} 
№ \\
Seq \\
No. \\
\end{tabular} & Farm, plot & Description & Type of soil \\
\hline 1 & $\begin{array}{l}\text { "Zolotaya } \\
\text { Balka" }\end{array}$ & $\begin{array}{l}\text { The relief is a billowy plain; humus (layer of } 0-20 \mathrm{~cm} \text { ) }-1.2 \% \text {, } \\
\text { mat. layer - deluvium; soil pH - 6.9; P2O5 }-1.4 \mathrm{mg} / 100 \mathrm{~g} \text { of } \\
\text { soil; K2O - } 17.5 \mathrm{mg} / 100 \mathrm{~g} \text { of soil; active Ca }-19.4 \mathrm{mg} / 100 \\
\mathrm{~g}\end{array}$ & $\begin{array}{l}\text { southern } \\
\text { chernozemic, low- } \\
\text { humus, high- } \\
\text { carbonate soil }\end{array}$ \\
\hline 2 & $\begin{array}{l}\text { Kober breed } \\
\text { shed }\end{array}$ & $\begin{array}{l}\text { Relief is lowering; humus - } 65 \mathrm{~cm} \text {; mat. layer - deluvium; } \\
\text { humus is } 1.55 \% \text {; } \mathrm{pH}-8.0 \text {; } \mathrm{P} 2 \mathrm{O} 5-0.9 \mathrm{mg} / 100 \mathrm{~g} \text { of soil; } \\
\mathrm{K} 2 \mathrm{O}-20.1 \mathrm{mg} / 100 \mathrm{~g} \text { of soil; active } \mathrm{Ca}-14.5 \mathrm{mg} / 100 \mathrm{~g}\end{array}$ & $\begin{array}{l}\text { southern } \\
\text { chernozemic, low- } \\
\text { humus soil }\end{array}$ \\
\hline 3 & $\begin{array}{l}\text { Magarach } \\
\text { agricultural } \\
\text { complex }\end{array}$ & $\begin{array}{l}\text { Carbonates in the } 0-60 \mathrm{~cm} \text { soil layer make up about } 7 \% \text {, with } \\
\text { a depth }(\text { of } 1.5 \mathrm{~m}) \text {, it increases to } 17-19 \% \text {. Humus }-2.5 \% \text {. } \mathrm{pH} \\
-8.1 \text { units. The total nitrogen content at the plantation depth is } \\
0.12-0.13 \% \text {. }\end{array}$ & $\begin{array}{l}\text { southern } \\
\text { chernozemic, low- } \\
\text { humus soil }\end{array}$ \\
\hline 4 & $\begin{array}{l}\text { "Chernomor } \\
\text { ets" farming } \\
\text { company }\end{array}$ & $\begin{array}{l}\text { The humus horizon reaches } 80-90 \mathrm{~cm} \text {. The humus content }(0- \\
20 \mathrm{~cm} \text { layer) is } 3.5 \% \text {. The gross nitrogen contains } 0.21- \\
0.30 \% \text {, hydrolysable } 5-11 \mathrm{mg} / 100 \mathrm{~g} \text {, which indicates a high } \\
\text { supply of mobile nitrogen. }\end{array}$ & $\begin{array}{l}\text { ordinary } \\
\text { chernozemic, } \\
\text { micellar- } \\
\text { carbonate, foothill } \\
\text { soils }\end{array}$ \\
\hline
\end{tabular}


4 areas which were not occupied by vegetation at the time of sampling and satellite acquisition were selected from 22 polygon areas for decoding, and there was no atmospheric interference for satellite images.

Analysis of the data from the archives of meteorological stations showed that the surface layers of the soil of all four studied areas were in an air-dry state. This circumstance made it possible to ignore the effect of soil moisture on its color during deciphering and subsequent analysis.

When preparing soil samples for photographing with a digital camera in laboratory conditions, they were dried to an air-dry state, and also ground to a size of $0.2-0.25 \mathrm{~mm}$.

During the shooting, artificial lighting with a stabilized voltage source was used, providing an accuracy of the supply voltage of $\pm 1 \%$. The soil sample was placed in a glass cuvette, compacted and leveled. A reference white sample was placed side by side and was subsequently used to correct the white balance in preparation for shooting and image processing.

The images obtained in the course of shooting in RAW (digital camera) and GeoTIFF (satellite images) were processed for subsequent analysis using the SIPS software package, as well as Photoshop CS6, which allow determining the average brightness in spectral channels (R, G, B). To increase the reliability, the images were obtained by an automatic series of 5 images, and then averaged.

\section{Results and Discussion}

It is advisable to carry out the analysis of the results of the experiment both as the results of laboratory shooting with a digital camera and the results of remote sensing from a satellite.

Spectral coefficients were calculated relative to the brightness of the reference. According to the results of laboratory studies, the highest brightness of the averaged values is observed in the red range $(\mathrm{R})$, the lowest - in the blue range (B). Comparative results are shown in Fig. 1.

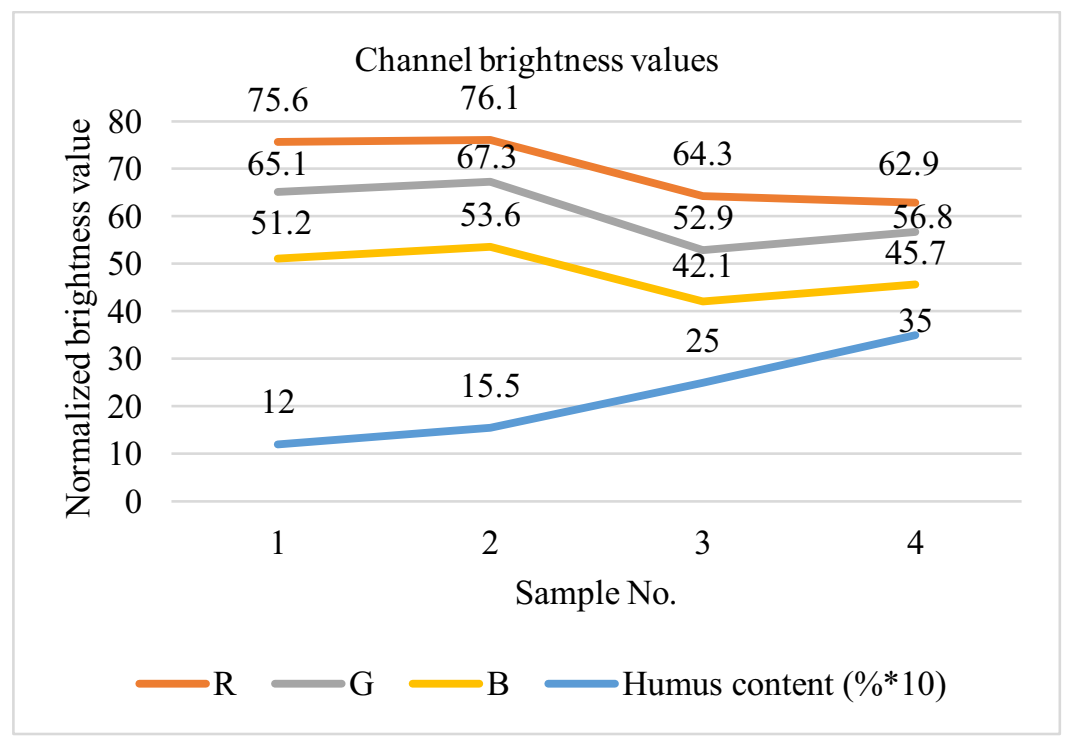

Fig. 1. Channel brightness values

Analysis of the results of statistical processing of laboratory shooting data suggests that the greatest correlation is observed between the humus content $(\mathrm{G})$ and the brightness of the 
red channel of a digital image. Thus, the $\mathrm{R}$ channel is the most informative for monitoring the level of humus in the soil.

For a more convenient assessment of the soil humus content, an analytical expression (regression equation) of the humus content in the soil was obtained for the dependence on the brightness level of the channel R:

$$
G=-0,136 R+11,651 .
$$

Also, satellite images of experimental sites were obtained from the Kanopus-V satellite, multispectral equipment (Figure 2).

A similar list of works related to the preliminary processing of photographic images and statistical processing of the results was carried out with satellite images. In this case, the following regression dependence was obtained (2):

$$
G=-0,011 R+9,21 .
$$

It follows from the analysis of the results obtained that the error in determining the value of the humus content does not exceed $20 \%$ (for laboratory images $-8.5 \%$ ), which shows the fundamental possibility of the considered remote monitoring.

It should be noted that despite the confirmation of the results of our experiment by a number of other researchers [14-16], the problem of continuous monitoring of the soil conditions in grape agrocenoses has not been solved yet. At the same time, monitoring the state of agricultural land is an essential element of the agro-industrial complex regulation system. At the same time, the most important requirement for monitoring systems is not even to increase the accuracy of remote assessment of the humus content in the soil but to monitor the dynamics of its change, and to timely inform industry leaders at the regional level about the negative dynamics of soil fertility for timely decision-making on agro-technological measures to restore soil fertility in the region.
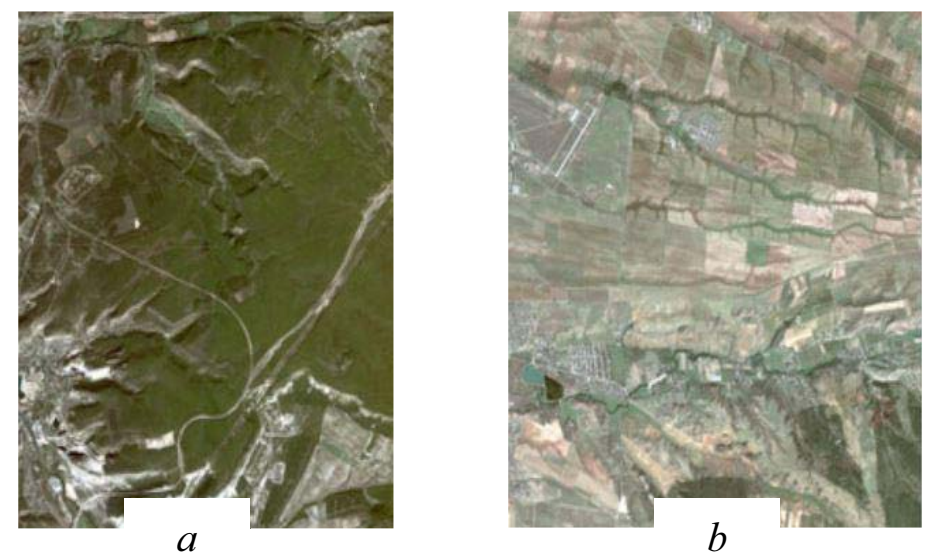

Fig. 2. Satellite images of experimental sites (a - sample 1, b - samples 2-4)

Taking into account the availability of world experience, the high level of development of satellite monitoring systems, the capabilities of modern computer technology, the creation of information systems (software and hardware systems) for the analysis and processing of satellite information is very promising. Our group of researchers and programmers is working towards the development of methods for automated monitoring of the soil conditions in an extensive region, processing large arrays of remote sensing satellite data, minimizing the participation of experts in the process of data interpretation. 
Taking into account the tasks solved by such an information system, the following structure of this system, which includes modules: archiving the received data of satellite observations, preliminary processing, and construction of composite images, thematic processing of the obtained data, and building maps of the soil conditions of grape agrocenoses, presentation of generalized results for users of the system (usually in the form of data from geographic information systems) can be proposed (Figure 3).

Receiving data from satellites can be done in various ways. In our opinion, the best way for regional monitoring systems is the method of obtaining data from specialized centers for receiving and processing data, since it allows to reduce the cost of purchasing special equipment and to receive data that have undergone sufficiently effective preliminary processing (if necessary), which makes it possible to reduce requirements to our own systems of preliminary information processing.

The data storage system solves the problem of storing archives, intermediate data of all stages of information processing, cataloged data. Archives can be operational, designed to work with information at the stage of preprocessing, and long-term, built on the principle of big data storages (Big Data with databases like noSQL), designed to store thematic information.

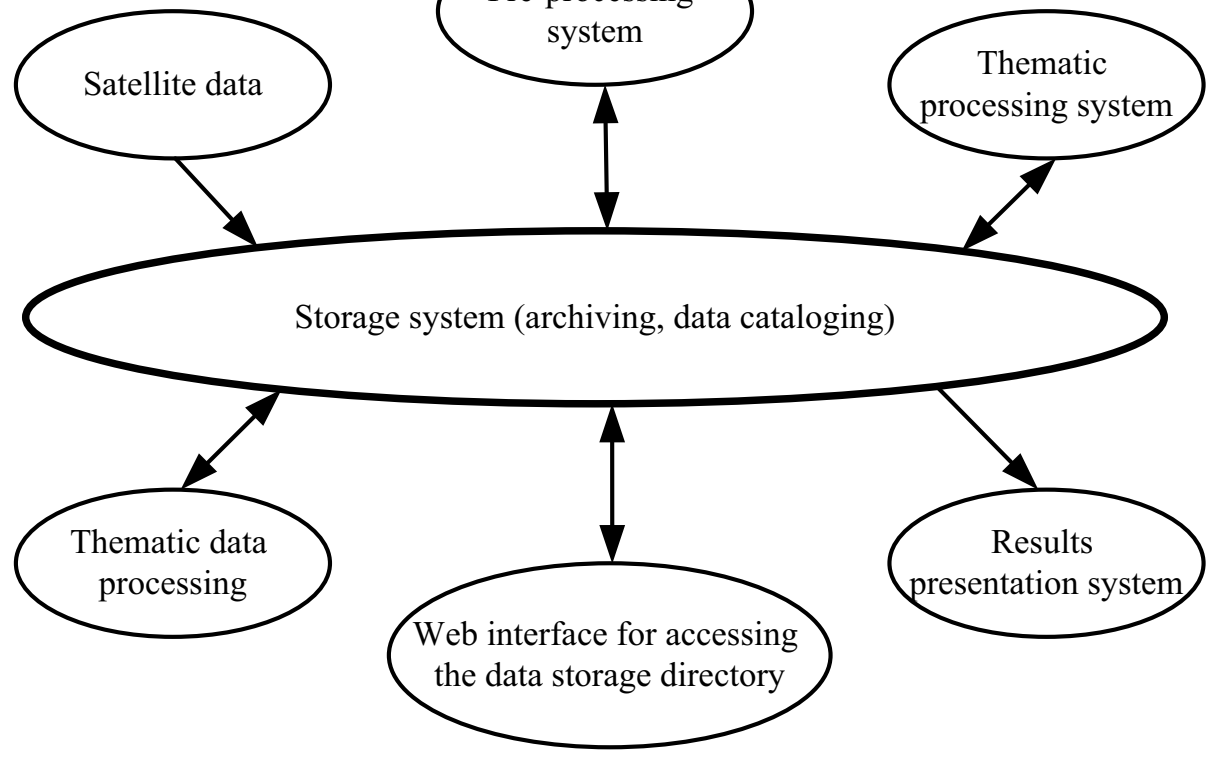

Fig. 3. The Structure of the Information System for Satellite Monitoring of Soil Conditions

The preliminary (primary) processing system provides high-precision geographic and temporal referencing of the obtained images, high-quality calibration of information, correction, taking into account the lighting conditions of the monitoring area, data conversion into the required formats for processing and placement in the archive.

The thematic processing system is focused on the use of fully automated methods and algorithms for data processing. Heterogeneous data processing procedures are used here, both in terms of the mathematical methods and the programming systems used. Sometimes specialized hardware is required to solve certain tasks in real time. For example, in our system for recognizing negative situations in terms of reducing the quality and fertility of soils, we used the author's method and clustering algorithm for problems of control based on a genetic algorithm with a k-means mutation operator, and at present, a multilayer neural network with 
backpropagation of errors is being developed, which will allow significantly improve the quality of clustering. As a result of the work of the specified module, information products necessary for the user are formed.

The results presentation system provides users with convenient and effective work with information in order to make a decision on measures to restore the quality and fertility of soils, as well as to control them.

The proposed structure of the information system will form the basis of the situational center of the regional agricultural production management body as an independent system or a subsystem of the situational center of a higher level.

\section{Conclusion}

As a result of the studies, the fundamental possibility of using satellite remote sensing methods for assessing the quality and fertility of soils in grape agrocenoses in the southern regions of Russia is shown.

It is shown that remote sensing methods are slightly (by 10-15 percent) inferior to laboratory methods in their accuracy parameters, but they allow monitoring soil fertility with a high degree of reliability. At the same time, this monitoring is provided almost in real time, which allows making operational managerial decisions on managing the restoration of soil fertility.

A structure is proposed and a meaningful description of the main blocks of the information system for satellite monitoring of soil conditions, which can be used as the basis for the created situational center for managing soil fertility of grape agrocenoses in the region or be a module of a situational center of a higher level, is given.

In the course of further research, an attempt will be made to use hyperspectral satellite equipment to solve the problem of monitoring and clustering and to build and train an artificial neural network for clustering the state of soils in the monitoring region.

The reported study was funded by RFBR, project number 20-016-00220.

\section{References}

1. I. Grishin, R. Timirgaleeva, E3S Web of Conferences 175, 06009 (2020) doi: $10.1051 / \mathrm{e} 3$ sconf $/ 202017506009$

2. J. Doran, E. Gregorich, Encyclopedia of soil science, vols I-III, 3rd edition, 2276-2279 (2017) doi: 10.1081/E-ESS3-120001719

3. P. Filippi, S. Cattle, M. Pringle, T. Bishop, Geoderma Regional, e00367 (2021) doi: 10.1016/j.geodrs.2021.e00367

4. J. Chen, W. Zhu, Y. Tian, Q. Yu, Science of The Total Environment 718, 137374 (2020) doi: 10.1016/j.scitotenv.2020.137374

5. Y. Ellili, C. Walter, D. Michot, P. Pichelin, B. Lemercier, Geoderma 351, 1-8 (2019) doi: 10.1016/j.geoderma.2019.03.005

6. R. Nerger, R. Funk, E. Cordsen, N. Fohrer, Aeolian Research 25, 135-147 (2017) doi: 10.1016/j.aeolia.2017.03.006

7. R. Jandl, M. Rodeghiero, C. Martinez, F. Cotrufo, F. Bampa, B. van Wesemael, R. Harrison, I. A. Guerrini, D. Richter, L. Rustad, K. Lorenz, A. Chabbi, F. Miglietta, Science of The Total Environment 468-469, 376-383 (2014) doi: 10.1016/j.scitotenv.2013.08.026 
8. H. Croft, N. Kuhn, K. Anderson, CATENA 94, 64-74 (2012) doi: 10.1016/j.catena.2012.01.00.

9. A. Denis, A. Stevens, B. van Wesemael, T. Udelhoven, B. Tychon, Geoderma 226, 94102 (2014) doi: 10.1016/j.geoderma.2014.02.015

10. Z. Venter, H.-J. Hawkins, M. Cramer, A. Mills, Science of The Total Environment, 145384 (2021) doi: 10.1016/j.scitotenv.2021.145384

11. T. Zhou, Y. Geng, C. Ji, X. Xu, H. Wang, J. Pan, J. Bumberger, D. Haase, A. Lausch, Science of The Total Environment 755(2), 142661 (2021) doi: 10.1016/j.scitotenv.2020.142661

12. X. Dou, X. Wang, H. Liu, X. Zhang, L. Meng, Y. Pan, Z. Yu, Y. Cui, Geoderma 356, 113896 (2019) doi: 10.1016/j.geoderma.2019.113896

13. M. Padilha, L. Vicente, J. Demattê, D. Loebmann, A. Vicente, D. Salazar, C. Guimarães, Geoderma Regional doi: 10.1016/j.geodrs.2020.e00253

14. H. Elbasiouny, Egypt. J. Soil. Sci. 58(4), 399-415 (2018) doi: 10.21608/ejss.2018.4741.1192

15. A. Bonfante, F. Terribile, J. Bouma, SOIL 5, 1-14 (2019) doi: 10.5194/soil-5-1-2019

16. J. Braun, A. Mirzabaev, Baltic Region 8(3), 33-44 (2016) doi: 10.5922/2079-8555-2016-3-3. 